\title{
The Financial Impact of Uncompensated Care in the Emergency Department
}

\author{
Pamela Treister $^{1}$, Ruth Conboy ${ }^{2}$, Lori Smittle $^{3}$, Christina Carter ${ }^{4}$, Leah Lucarelli ${ }^{5}$, Erin Kampa ${ }^{6}$ \\ ${ }^{1}$ Department of Nursing, New York Institute of Technology, Old Westbury, New York, USA \\ ${ }^{2}$ Department of Student Affairs, Philadelphia College of Osteopathic Medicine, Philadelphia, USA \\ ${ }^{3}$ Westchester County Department of Health, Westchester, New York, USA \\ ${ }^{4}$ Workforce Analytics for Healthcare, Kronos Inc., Arizona, USA \\ ${ }^{5}$ Cornell Scott-Hill Health Center, New Haven, Connecticut, USA \\ ${ }^{6}$ Norwalk Community Health Center, Norwalk, USA
}

\section{Email address:}

ptreiste@nyit.edu (P. Treister), ruthco@pcom.edu (R. Conboy), lorismittle@gmail.com (L. Smittle), ccarterrn@aol.com (C. Carter), llucarelli@cornellscott.org (L. Lucarelli), eekampa@gmail.com (E. Kampa)

\section{To cite this article:}

Pamela Treister, Ruth Conboy, Lori Smittle, Christina Carter, Leah Lucarelli, Erin Kampa. The Financial Impact of Uncompensated Care in the Emergency Department. International Journal of Economy, Energy and Environment. Vol. 2, No. 6, 2017, pp. 104-108.

doi: $10.11648 /$ j.ijeee.20170206.13

Received: October 30, 2017; Accepted: November 20, 2017; Published: December 14, 2017

\begin{abstract}
Prior to 1986, emergency department staff was both morally and ethically obligated to provide care that included the stabilization and treatment of all patients who presented to the emergency department, regardless of their ability to pay. In 1986, this moral and ethical obligation became federal law with the passage of the Emergency Medical Treatment and Labor Act (EMTALA), which required any patient coming to an emergency department be stabilized and treated regardless of their insurance status or ability to pay [1] [2]. Hospital emergency departments are a critical entry point into the American health care system. The patient population is a combination of the privately insured, including high deductible health plans, the uninsured, and the underinsured. Although emergency treatment is covered under EMTALA, hospitals are left to deal with the bills accumulated from non-emergent daily medical care. The increase in volume places tremendous burden on hospital emergency departments, with high overhead and fixed costs. Many facilities cannot keep up with costs and are forced into bankruptcy, leading to overcrowding in nearby hospitals. More thought must be placed on how hospitals can bear the burden of uncompensated care. Access to care is not enough; it's crucial that care be affordable. Addressing uncompensated care in the emergency department can be done successfully. The staff is proficient in saving lives, now they must learn to put the same effort into saving money.
\end{abstract}

Keywords: EMTALA, Affordable Care Act, Uninsured, Underinsured, Undocumented Immigrants, Emergency Care

\section{Introduction}

Prior to 1986, emergency department staff was both morally and ethically obligated to provide care that included the stabilization and treatment of all patients who presented to the emergency department, regardless of their ability to pay. In 1986, this moral and ethical obligation became federal law with the passage of the Emergency Medical Treatment and Labor Act (EMTALA), which required any patient coming to an emergency department be stabilized and treated regardless of their insurance status or ability to pay [1] [2].
Hospital emergency departments are a critical entry point into the American health care system. According to the National Hospital Ambulatory Medical Care Survey (NHMCS), there were 136 million emergency department visits made in the United States in 2011. While emergency department visits have continued to increase over the past fifteen years (Centers for Disease Control and Prevention, 2015), the patient population remains a combination of the privately insured, including high deductible health plans, the uninsured, and the underinsured. The Healthcare cost and Utilization Project, reports the payer breakdown of U. S. 
Emergency Department visits in 2011 as follows: 29\% were billed to private insurance, $27 \%$ to Medicaid, $22 \%$ to Medicare, and $16 \%$ had no insurance coverage. Medicare was the most common payer for visits that led to admission and for those visits that led to discharge, and 18\% were uninsured [3]. Although emergency treatment is covered under EMTALA, hospitals are left to deal with the bills accumulated from non-emergent daily medical care. The increase in volume places tremendous burden on hospital emergency departments, with high overhead and fixed costs. Many facilities cannot keep up with costs and are forced into bankruptcy, leading to overcrowding in nearby hospitals. More thought must be placed on how hospitals can bear the burden of uncompensated care. Some of these uninsured are the undocumented immigrant population, who are ineligible for federally funded programs such as Medicare, Medicaid, and insurance through the Affordable Care Act [4].

\section{Unauthorized or Undocumented Immigrants}

The Affordable Healthcare Act (ACA) excludes undocumented immigrants (also called unauthorized or illegal). Legal (or authorized) immigrants currently have to wait five years to become eligible for Medicare or CHIP (Children's Health Insurance Program). Publicly funded safety-net providers (including public and not for profit hospitals) provide some access to health care for undocumented immigrants. Under EMTALA, hospitals are required (if they receive Medicaid funding), to provide free medical screening exams to everyone, to determine the type of care necessary to stabilize patients experiencing emergency conditions. Costs incurred by hospitals have been offset by Disproportionate Share Hospital Funds (DSH) as well as by donations. Under ACA, $75 \%$ of DSH is being cut. Hospitals may ultimately opt to pay a fine rather than pay for emergency medical procedures for undocumented immigrants [5]. This could result in a significant public health issue, as more individuals are not receiving the care they need, putting themselves and those in their communities at risk.

There are approximately 11.4 million undocumented immigrants living in the United States. The classic image of undocumented immigrants is of an individual or family sneaking across the border in the dead of night. In reality, half of undocumented immigrants come across the border and the other half enter the U. S. legally to work, or applied for tourist visas and overstayed their residency periods [6]. Undocumented immigrants may avoid seeking health care services because of fear of deportation.

Emergency Medicaid (mostly used by undocumented immigrants) costs approximately $\$ 2$ billion dollars/year. This aid covers emergency care and delivery of babies. One premature birth, which can result from a lack of prenatal care, can cost the equivalent of one dozen healthy births. With proper identification of an at risk mother, and adequate pre-natal care, the incidence of low birth weight babies can be decreased [7]. Definitions of emergency care and the scope of services available vary by state. In New York, emergency Medicaid may be used to provide chemotherapy and radiation to undocumented immigrants. In NY, California, and North Carolina, it may be used to provide outpatient dialysis to undocumented patients [8].

According to Sultan (2014), in the past 40 years, the United States has had a significant influx of undocumented immigrants from developing countries, more than many of its European contemporaries. The US has a responsibility to lay the groundwork for how dozens of other countries treat undocumented immigrants. One solution would be for industries or states to model their responses after some creative programs that already exist.

ROC-MD is an example of a creative solution that exists in Southern California [9]. ROC-MD provides health care coverage to undocumented persons. It was started by the Restaurant Opportunities Center of LA \& St John's Well Child and Family Center. Family members pay $\$ 25.00$ each month and can use medical services at one of St. John's Clinics. This opportunity for primary and preventative health care can help avoid an exacerbation of symptoms and costly emergency room visits. Legal immigrants and other restaurant workers who don't meet the criteria or cannot afford coverage under the healthcare law are also eligible [10].

There are some other solutions for the undocumented immigrants without insurance. A pilot program in Hennepin County, Minnesota saved $11 \%$ in medical costs in 2012 by involving social service departments with their "super utilizers", complex patients who frequent the emergency department [11]. A similar model applied to undocumented immigrants could be effective, provided they were eligible for the social services offered. My Health LA (MHLA) is a no cost health care program for people who live in Los Angeles County, California. It is free to individuals and families who do not have or are ineligible for health insurance. It is provided by non-profit clinics.

Still another solution is being proposed on the state level. Currently, there is a proposal (SB4) for a law in California [12]. It would allow undocumented immigrants the ability to purchase insurance without federal subsidies. A potential solution to this national healthcare issue could be to reallocate federal funds towards prevention and the appropriate management of chronic health conditions for undocumented immigrants, rather than only supporting episodic, expensive, life preserving care. Simultaneously, immigration issues need to continue to be addressed. Another broader recommendation comes from The American College of Physicians (2011): if immigration is a national issue, so too should be the access and delivery of healthcare. Currently individual states determine what services will be made available to undocumented immigrants. This creates a patchwork of services that is ineffective and could lead to undocumented immigrants migrating towards states with more generous plans, causing hardship on those particular 
states and health care providers. Those opposed to footing the bill for health care for undocumented immigrants may be blind to the fact that through EMTALA taxpayers are already absorbing these costs through higher prices, premiums and taxes.

Potential public health issues or crises can be averted by providing comprehensive primary care (including vaccinations), prenatal care, injury prevention initiatives, toxic exposure prevention, and disease management, rather than strictly emergency care. One third of emergency room physicians provide more than 30 hours of EMTALA related care each week, according to the American College of Emergency Physicians.

\section{Electively Uninsured}

In 2007, 45.7 million people in the United States-or 17.2 percent of the nonelderly U. S. population-were without any form of health insurance [13]. Our healthcare system had grown accustomed to this population - absorbing costs of emergent care that would never be paid, usually the result of preventive and primary care that had never been accessed. The nature of the uninsured patient population has changed with the full rollout of the Affordable Care Act (ACA) in 2014.

As of March, 2015, the numbers of uninsured adults were estimated to be 15 million lower than the number of uninsured adults in September 2013, a decrease in the uninsured rate of 42.5 percent. Coverage gains have been especially large among adults in states that expanded Medicaid and among adults targeted by the ACA's Medicaid expansion and Marketplace subsidies [14].

In evaluating the impact of emergency care costs for the uninsured, it will help to understand the nature of the population who continue to be uninsured. Although it may be imagined that this population may be gambling that the cost of any needed care would be less than the penalties, the reality is that this population represents the working poor (100\%-400\% of poverty) and the available coverage options could cost approximately $50 \%$ or more of their take home pay [15]. Living in a state that hasn't expand Medicaid coverage increases the risk that costs will outweigh benefits and risks for adults without coverage [16]. Those who have literacy and numeracy issues impacting their ability to navigate the healthcare marketplace including those who don't know they are eligible or are misinformed may think they are not eligible, too [17].

However, there are some potential solutions for those that are electively uninsured. These include similar interventions to other populations such as good information and access to assistance. Since many of the "working poor" are from this specific population who are electively uninsured, services need to be offered during off hours in order to increase accessibility to health care. These will not be the people who will typically take off work, as they need the money, unless there is an emergency. They are thinking of the insurance they do not have and will try to hold off on any possible medical visits as long as possible. Living in a state that hasn't expanded Medicaid coverage increases the risk that costs will outweigh benefits and risks for adults without coverage [16].

However, engaging these people is essential in order to educate this target population, who may not realize that they may be eligible, including Emergency care. Engaging the individual patient at every opportunity is a more effective strategy than waiting until there is a dire need for care [18].

Other potential solutions include a Warm Hand-off to a facilitator for sign-up support during and ED visit. This referral to a local primary care provider or community health center with a sliding scale for uninsured patients for continued preventive and primary care may be the bridge which is necessary for the patient. Establishment with a "medical home" has been revealed in studies to affect no less than an $11 \%$ reduction in use of ED services and $12 \%$ fewer hospitalizations for both adult and pediatric patients [19]. If there is continued institutional financial planning for the care of uninsured patients through charitable grants and government safety net programs, this will be helpful. Although the need may be reduced, there will always be someone in need [20].

\section{The Underinsured: High Deductible Health Plans}

As healthcare costs rise, employers are increasingly turning to high deductible health plans (HDHP) in which families share the costs through insurance premiums, deductibles and copayments [21]. This is an affordable way for employers to offer high quality health insurance plans to their employees, without the escalating costs of premiums. HDHPs require full cost payments for most services by the consumer until the annual deductible has been met. Health plans must cover preventative services at no cost with the new 2010 Patient Protection and Affordable Care Act (ACA) [22].

From 2006 to 2010 the percentage of employees covered by HDHPs with a deductible of at least $\$ 1000$, increased from 10 percent to 27 percent [23]. In 2010, average deductibles for commercial health insurance plans ranged from $\$ 601$ to $\$ 1903$ for individuals and $\$ 1321$ to $\$ 3780$ for families [23], though the maximum out of pocket burden in 2015 is capped at $\$ 6,450$ for self-only coverage or $\$ 12,900$ for family coverage (IRS. gov).

In 2018, as part of the ACA, there will be a 40 percent tax, known as "The Cadillac Tax" for insurance companies who enroll customers in plans that cost more than the designated threshold in an effort to reduce "overly generous health insurance coverage" [22]. This Cadillac Tax, is expected to further increase as employers push towards coverage with high deductibles and cost sharing to help insurers cut costs and avoid taxation [22].

In theory, the creation of a high deductible health insurance plan is not only beneficial to employers, but allows its members "consumer-directed health care" in which the customer is given more responsibility for the costs of 
healthcare [24]. This consumer choice is one of the foundations of the $2010 \mathrm{ACA}$ in which advocates believe that consumer control and choice within healthcare will make the consumer "more likely to 'economize' their use on low-value medical services and empowers them to take more responsibility for their health and for health behaviors" [22].

Though growing in popularity due to the ACA, high deductible health plans are not a new health insurance option in the United States. For the past few decades there has been research around utilization of healthcare services with patients facing high cost sharing responsibility. The RAND Health Insurance Experiment of 1971 - 1986 found that patients who are facing high-level cost-sharing reduced overall utilization by approximately 33 percent and total spending by about 30 percent [23].

In a 2011 study conducted by Galbraith et al, it was shown that vulnerable populations such as those with chronic diseases are at particular risk for financial burden of high deductible health care plans. According to the 2007/2008 National Health Interview Survey, 70 percent more adults in HDHPs had unmet medical or prescription drug needs compared to adults in traditional health insurance plans [23]. The financial burden associated with health care costs are not only contributing to patients delaying or neglecting their healthcare needs altogether, but are also forcing the insured to have problems paying other bills, accrue debt, face bankruptcy, and add stress to the family structure [21].

Financial stress for patients has a large impact on the bottom line of an emergency room and hospital. According to a study conducted in 2011 by Borah et al [25], members of high deductible health plans had no reduction or increase in the number of emergency room visits for the time period of the study, though did have lower outpatient visits and increased inpatient visits. This means that the patients who had high out-of-pocket expenses were less likely to seek out care when slightly ill. As a result, the patients presented to the hospital sicker than those who had sought care earlier in the disease process.

These emergency room visits and inpatient stays are costly to the hospital. The insurance company only pays the bill after the deductible has been reached. This leaves a gap of payment for the hospital. This, in essence, is turning an insured population into a self-pay population for the hospital. The result is revenue that was once generated and paid from an insurance company is now potentially lost due to patient financial burden and increasing cost of the hospital to bill and collect funds.

The solutions to help hospitals receive revenue from those covered by high deductible health plans, involves helping the covered members have liquid funds to pay their medical bills. HDHPs are often used in conjunction with Health Savings Accounts (HSAs), which allow consumers to put pre-tax money into a specialized savings account that can then be used to pay for out-of-pocket healthcare costs [21]. Members are allowed to contribute in the year 2015 up to $\$ 3350$ for an individual and $\$ 6650$ for a family (IRS. gov). This amount may be rolled over from year to year so the member does not lose out on any money not used. By setting aside money into this specialized account, members will have access to money devoted strictly to medical expenses, which will hopefully help to minimize the out of pocket burden for hospital bills.

Another solution is to have employers contribute to the HSAs on behalf of their employees. With the money the employer will save by switching to a HDHP for its employees, it can put some of the saved money into HSA accounts to help the members have less financial burden when it comes time to pay their medical bills. This solution is much harder to enforce or lobby as there is no regulation stating employers must contribute on behalf of their employees. Employers do not need to offer HSA accounts in conjunction with the offered health insurance plans.

A revenue generating idea for hospitals is to increase business by placing high importance on excellent customer service in billing and collections for self- pay patients [26]. If "practices are perceived to be insensitive, particularly at a time of discharge and later in the business office process, they could have a corrosive effect on the patient's overall satisfaction with the hospital" [26]. If dissatisfied with their experience, patients will be less likely to return to that same hospital in the future for healthcare needs and less likely to recommend that hospital to friends and families.

\section{Conclusion}

Financial forecasting must include provisions that address uncompensated care in the emergency department. Undoubtedly the ACA has increased the number of insured. Establishing a sliding scale medical home that promotes health through education is a viable alternative to the emergency department for the underinsured, uninsured, and the immigrant population. HDHPs place such financial burdens on the insured that this often becomes a deterrent when seeking healthcare. Medicaid, Medicare, and other third party payers should work together with emergency departments to insure timely payment. Access to care is not enough; it's crucial that care be affordable. Addressing uncompensated care in the emergency department can be done successfully. The staff is proficient in saving lives, now they must learn to put the same effort into saving money.

\section{References}

[1] EMTALA. (2014). American College of Emergency Physicians. Advance online publication. www.acep.org. EMTALA (2005).

[2] American College of Emergency Physicians, http://www.acep.org/content.aspx?id=25936, American College of Physicians, 2011,

http://www.acponline.org/advocacy/where_we_stand/assets/na tl_immigration.pdf.

[3] Weiss, A. J., Wier, L. M., Stocks, C., \& Blanchard, J. (2014). Overview of emergency department visits in the United States, 2011. 
[4] Gusmano, M. J. (2012). Undocumented immigrants in the United States: U. S. health policy and access to care. Health Services Los Angeles County,

[5] Sultan, B. The domestic and international ethical debate on rationing care of illegal immigrants.

[6] Skerry, P. Splitting the difference on illegal immigration. National Affairs.

[7] Redding, S., Conrey, E., Porter, K., Paulson, J., Hughes, K., \& Redding, M. (2015). Pathways community care coordination in low birth weight prevention. Maternal and Child Health Journal, 19, 3, 643-650.

[8] Galewitz, P. How undocumented immigrants sometimes receive medicaid treatment. PBS Newshour. http://www.pbs.org/newshour/rundown/how-undocumentedimmigrants-sometimes-receive-medicaid-treatment/ February 13, 2013.

[9] "ROC M. D. Affordable Health Care For All," http://rocunited.org/our-work/membership-leadershipdevelopment/roc-md/.

[10] Gorman, A. L. A. program offers healthcare for illegal restaurant workers. Los Angeles Times. May 03, 2012.

[11] Tavernise, S. (2015, Mar 23, 2015). Ounce of prevention: Health care systems try to cut costs by aiding poor. New York Times.

[12] Graves, S. Senate bill 4-health center for all-set for first hearing. California Budget and Policy Center $\mathrm{http} / / /$ calbudgetcenter.org/blog/senate-bill-4-health-care-forall-set-for-first-hearing/ April 14, 2015.

[13] IOM (Institute of Medicine). (2009). America's uninsured crisis: Consequences for health and health care. Washington, DC: The National Academies Press.

[14] Long, S., Karpman, M., Kenney, G., Zuckerman, S., Wissoker, D., Shartzer, A., and Hempstead, N. (March 2015). Taking stock: Gains in health insurance coverage under the ACA as of March 2015. Washington, DC: Urban Institute.

[15] Chilton, J. (2014, Jan 27). "Caught in coverage gaps". Wyoming Tribune-Eagle.

[16] Garfield, R., Damico, A., Stephens, J., \& Rouhani, S. (4/17/2015). The coverage gap: Uninsured poor adults in states that do not expand Medicaid - an update. Menlo Park, CA: The Henry J. Kaiser Family Foundation.

[17] Long, S., Shartzer, A., \& and Politi, M. (October 2014). Low levels of self-reported literacy and numeracy create barriers to obtaining and using health insurance coverage. Washington, DC: Urban Institute.

[18] Chen J, Mullins CD, Novak P, Thomas SB. (2015). Personalized strategies to activate and Empower Patients in Health Care and reduce health disparities. Health Education and Behavio.

[19] DeVries, A., Li, C., Sridhar, G., Hummel, J., Breidbart, S., \& Barron, J. (2012). Impact of medical homes on quality, healthcare utilization, and costs.. American Journal of Managed Care, 18 (9), 534-44.

[20] Adepoju, O., Preston, M., \& Gonzales, G. (2015). Health care disparities in the Post-Affordable Care Act era. American Journal of Public Health, e1-e3. [Epub ahead of print]. doi:10.2105/AJPH.2015.302611

[21] Galbraith, A., Ross-Degnan, D. Soumerai, S., B., Rosenthal, M., B., Gay, C., \& Lieu, T., A. (2011). Nearly half of families in high-deductible health plans whose members have chronic conditions face substantial financial burden. Health Affairs, 30 (2), 322-331. doi:10.1377/hlthaff.2010.0584.

[22] Oberlander, J. (2014). Between liberal aspirations and market forces: Obamacare's precarious balancing act. Journal of Law, Medicine \& Ethics, 42 (4), 431-441. doi:10.1111/jlme.12166.

[23] Reiss, S., Ross-Degnan, D., Zhang, F., Soumerai, S., Zaslavsky, A. M., Wharam, J. F. (October, 2011) Health Serv Res. 2011 Oct; 46 (5): 1382-1401. doi: 10.1111/j.14756773.2011.01252.x.

[24] Lave, J. R., Men, A., Day, B. T., Wang, W., \& Zhang, Y. (2011). Employee choice of a high-deductible health plan across multiple employers. Health Services Research, 46 (1), 138-154. doi:10.1111/j.1475-6773.2010.01167.x.

[25] Borah, B. J., Burns, M. E., \& Shah, N. D. (2011). Assessing the impact of high deductible health plans on health-care utilization and cost: A changes-in-changes approach. Health Economics, 20 (9), 1025-1042. doi:10.1002/hec.1757.

[26] Levin, S. (2011). Acknowledging the importance of BAI accounts. Hfm (Healthcare Financial Management), 65 (9), 90 . 